\title{
The Application of Skin Care Product in Melasma Treatment
}

\author{
Yu Wang \\ Jianmei Zhao \\ Lu Jiang \\ Yunzhu Mu
}

Department of Dermatology, The Affiliated Hospital of North Sichuan Medical College, Nanchong, Sichuan Province, 637000, People's Republic of China
Correspondence: Yunzhu Mu Email hymyz@126.com

\begin{abstract}
Melasma is an acquired and chronic hyperpigmentation disorder which is recognized as one of the most psychologically distressing and difficult to cure forms of skin hyperpigmentation. It is associated with substantial quality of life impairments. Treatments of melasma include local application, oral medication, physical laser therapy and program combination therapy. However, routine treatment usually leads to the damage of skin barrier function, resulting in adverse reactions such as erythema, pruritus, post-inflammatory pigmentation and even scar. Skin care products contain a variety of active ingredients, which are widely concerned by cosmetic dermatologists because of high safety, good tolerance and the effect of improving the damaged skin barrier. Using skin care products alone or in combination with routine treatment not only can improve the curative effect for melasma, reduce side effects and recurrence rate, but also improve patient satisfaction. This article mainly describes the application of skin care products in the treatment of melasma.
\end{abstract}

Keywords: skin care product, melasma, treatment

\section{Introduction}

Melasma is an acquired disorder of hyperpigmentation that typically presents as irregular pigmented spot on the sun-exposed areas of skin, especially on the face and neck. ${ }^{1}$ Its pathogenesis has not been fully elucidated. The triggers for melasma are diverse, including inheritance, ultraviolet light, inflammation, oxidative stress, disruption of the skin barrier, angiogenesis and estrogen. ${ }^{1}$ The prevention of sunlight and hyperpigmentation is the therapeutic goal of melasma, but melasma is intractable and readily recurrent currently. ${ }^{1,2}$ Despite available multimodal treatments, which include various topical agents, systemic agents, and laser therapy, treatment outcomes have been disappointing. To this date, no single therapeutic approach has been proved entirely effective. Skin care products are daily chemical industrial products that are spread over human skin and its appendages by smearing, spraying or other similar methods to clean, skin care, beauty, sunscreen, and modify. $^{3}$ Impairment of the skin barrier function is a significant cause of melasma. ${ }^{4}$ At the same time, routine treatments could lead to various adverse effects, such as impairment of the skin barrier function, inflammation, postinflammatory pigmentation, scar and depigmentation. ${ }^{5}$ Skin care products contain many active ingredients, for example, aloe, oleracea, nicotinamide, titania, hyaluronic acid that possess a variety of beneficial effects in whitening, moisturizing, antiinflammatory and sun protecting. ${ }^{6}$ Consequently, using skin care products not only can improve melasma lesions and reduce the incidence of adverse reactions but also 
can prevent recurrence as maintenance treatment. ${ }^{5}$ Now, more and more studies indicate that skin care products combined with routine treatment can improve the efficacy, tolerability and compliance in patients with high safety.

\section{Sunscreen Products}

UV light is a well-known extrinsic factor in the occurrence and development of melasma. Histopathology of melasma showed increased melanin content in all layers of the epidermis. ${ }^{7}$ Melanin is synthesized by hydroxylation of L-phenylalanine to L-tyrosine or directly from L-tyrosine. ${ }^{8}$ Any factor involved in the pathway for melanin synthesis will affect the synthesis of melanin. First of all, ultraviolet radiation up-regulate the expression of microphthalmia-associated transcription factor (MITF), tyrosinase (TYR), tyrosinase-related protein 1 (TRP1) and dopachrome tautomerase (DCT) in skin. ${ }^{9}$ Among these, MITF serves a crucial function in the synthesis of melanin. ${ }^{8}$ Secondly, UV light stimulates melanogenesis by activating tyrosinase expression through various signaling pathways, such as MSH/cAMP signaling pathways, SCF/KIT signaling pathways and so on. ${ }^{10,11}$ UV radiation can also trigger keratinocytes produces and releases histamine, when histamine binds to H2-receptors, tyrosinase is activated to induce melanin production. ${ }^{12,13}$ UV light causes basement membrane damage by activating MMP2 and MMP9 to degrade type IV collagen and type VI collagen, the major component of the basement membrane. ${ }^{14}$ Basement membrane damage enables melanocytes and melanolipofuscin granules to move down into the dermis, making melasma persistent and recurrent. ${ }^{15}$ Finally, UV light can influence skin fatty acid metabolism that could bring about skin-barrier disruption. ${ }^{16}$ Therefor, rational and effective use of sunscreens can reduce the production of melanin, avoid the occurrence of skin inflammation, protect the skin barrier, and prevent the recurrence of melasma, which is an important adjuvant therapy and the basis for the treatment of melasma. At the same time, some moisturizing ingredients added to sunscreens can also help repair skin barrier function. ${ }^{17}$

A recent study showed that 100 participants were required to apply sunscreen (Garnier White Complete ${ }^{\circledR} \mathrm{SPF} 19 \mathrm{PA}+++$ ) during the daytime every 3 hours (approximate $3 \mathrm{~mL}$ each time) and found that modified Melasma Area Severity Index (mMASI) score, Hi-MELASQOL score decline, and mMASI score was marginally associated with Hi-MELASQOL score after 12 consecutive weeks of treatment. ${ }^{18}$ This study confirmed that use of sunscreen alone can improve the skin lesions and the quality of life of patients with melasma. In one study by Lakhdar et al, ${ }^{19}$ the researchers have found that the clinical improvement was observed in 8 out of 12 volunteers who were affected by a pre-existing melasma and regular application of sunscreen in 185 pregnant women could prevent melasma and only five new cases of melasma occurred. The Indian expert panel recommended that patients with melasma use broadspectrum anti-UV A and B sunscreens with physical blocking agents like $\mathrm{ZnO}$ and $\mathrm{TiO} 2$ (SPF $>30$ ) regularly. ${ }^{2}$ Especially for pregnant patients, sunscreen may be the only therapeutic option available. ${ }^{20}$ At present, visible light(VL) is also thought to be involved in the pathogenesis of melasma, so anti-VL agents should be added to sunscreen. ${ }^{21}$

\section{Whitening Products}

As mentioned previously, melasma is characterized by excessive accumulation of melanin in the epidermis and dermis. Melanin is synthesized and stored in melanocytes through a series of oxidative reactions, and through dendritic processes of melanocytes transfer to the neighboring keratinocytes, then some brown spots and patches appear on the surface of the skin, and tyrosinase is the key enzyme in the synthesis of melanin. ${ }^{22}$ Whitening products contain arbutin, licorice flavone, tranexamic acid, vitamin $\mathrm{C}$, green tea extract, and so on which can whiten, anti-freckle and reduce pigmentation by inhibiting tyrosinase and other functions. ${ }^{3}$ Niacinamide(NAM), the water-soluble, active form of vitamin B3, can inhibit the transfer of melanosomes to keratinocytes by regulating protease activated receptor-2 (par-2). ${ }^{23}$ Vitamin $C$, a natural antioxidant, interacts with copper ions to inhibit tyrosinase activity, which also plays a significant role in collagen synthesis and possess photoprotection effect. ${ }^{24}$ Vitamin $E$ has been proved to interfere lipid peroxidation of melanocyte membranes, increase intracellular glutathione content, and inhibit tyrosinase activity. ${ }^{23}$ A double-blind, randomized, parallel-group clinical trial conducted by Bronzina et $\mathrm{al}^{25}$ have showed that the experimental group received the combination of cosmetic products: Neotone ${ }^{\circledR}$ serum and Neotone ${ }^{\circledR}$ Radiance SPF 50+ (ISISPHARMA, Lyon, France) improve the severity of melasma more effectively and with less side effects compared with the control group only received $4 \%$ HQ cream (same formulation as Neotone ${ }^{\circledR}$ serum but the active ingredient is replaced by $4 \% \mathrm{HQ}$ ) and an SPF 50+ cream (same formulation as Neotone ${ }^{\circledR}$ Radiance, with the same UV filters but without the actives). To sum up, adding nicotinamide, vitamin $\mathrm{C}$, vitamin $\mathrm{E}$ and other whitening ingredients to skin care products can reduce the production of melanin, thus improve the skin lesions of patients with melasma and prevent post-inflammatory hyperpigmentation, which is an important auxiliary means for the treatment of melasma. 


\section{Moisturizing Products}

Moisturizing skin care products are effective which can increase the moisture content of the epidermis, help restore barrier function of the skin, reduce the dryness and peeling of the skin, and make skin smooth. ${ }^{26}$ Moisturizing skin care products are mainly divided into four categories: occlusives, humectants, emollients and rejuvenators. 1) Occlusives can form a hydrophobic layer on the surface of the skin to avoid the loss of water, such as petrolatum, dimethicone. 2) Humectants are able to increase the moisture content of the skin by attracting water from the dermis and the environment, such as hydroxy acids, propylene glycol(glycerin), and urea. 3) Emollients can improve the look and texture of skin by filling in the crevices between keratinocytes. Most of this skin care products are essential fatty acids in natural oils, such as linoleic acid. 4) Rejuvenators are used to supplement essential proteins in the skin, such as collagen, keratin and elastin. ${ }^{27} \mathrm{~A}$ study conducted by Kang et al showed that the skin barrier function of melasma was disrupted and the transdermal epidermal water loss (TEWL) of the melasma was not different from that of the surrounding ( $13.5 \pm 4.0$ vs $15.6 \pm 4.6, \mathrm{P}=0.210$ ), but the recovery rate of barrier at the lesional skins was significantly delayed ( $76.3 \pm 12.3 \%$ vs $62.5 \pm 22.8 \%, \mathrm{P}=0.043) .{ }^{9}$ Once the skin barrier is destroyed, the moisturizing capabilities will decrease, therefore a vicious circle forms. ${ }^{28}$ Peter et $\mathrm{al}^{29}$ proposed that dryness and destruction of skin barrier will lead to skin pigmentation. At the same time, the routine treatment of melasma, like laser therapy, local application, will also disrupt the skin barrier function. ${ }^{5}$ Therefore, using moisturizing products daily can help restore skin barrier function and improve the skin lesions of patients with melasma. Xiaofeng Huang et $\mathrm{al}^{28}$ have found that TEWL decreased, the skin water content increased, and the skin became whitened after using Vaseline moisturizing lotion (Unilever company) alone for 2 months in chloasma patients.

\section{Medical Skin Care Product}

Medical skin care product, also called cosmeceutical, is active product with drug or similar drug characteristics sold as cosmetics, and is a special cosmetic between traditional cosmetics and medicine. Compared with traditional cosmetics, it has better safety, stability, comfort and effectiveness which main mechanism is to increase the water content and lipid composition of the stratum corneum to repair epidermis, rebuild skin barrier and anti-inflammation. ${ }^{3}$ A variety of components in medical skin care product play an auxiliary role in the treatment of melasma. For example, tranexamic acid has anti-inflammation and anti-angiogenic effect. ${ }^{30}$ Resveratrol possesses a large number of pharmacological activities, including inhibition of tyrosinase activity, antiinflammatory, anti-oxidant and UV Protectant. ${ }^{31}$ The extracts from orchid (phenolic compounds) possess antioxidant properties. ${ }^{32}$ Arbutin is a hydroquinone glycoside with great capacity to reduce tyrosinase activity. ${ }^{33}$ Soybean extract possess antioxidant properties and can suppress melanosome metastasis. ${ }^{34}$ Extracts of Aloe (aloin et al) are known to exhibit moisturizing, anti-inflammatory, and antioxidant properties. They can also promote wound healing and inhibit tyrosine convert into DOPA. ${ }^{35,36}$ The extract of Camellia sinensis has the effects of moisturizing, anti-inflammation, anti-oxidation and inhibiting tyrosinase activity. ${ }^{37}$ Cysteamine has the effects of anti-oxidation and inhibition of tyrosinase and peroxidase activity. ${ }^{38}$ Wenli $\mathrm{Lu}^{39}$ conducted a 12-week clinical trial in China which proved that the whitening cream contain some new whitening extract of prinsepia utilis, Portulaca oleracea, China camellia, sanchi can effectively improve melasma with no obvious adverse reaction in clinic. In summary, the rational use of medical skin care products for patients with melasma not only can increase skin moisture content, restore skin barrier function, but also help to reduce pigmentation with less side effects. Medical skin care product is expected to become a new choice for maintenance treatment for patients with melasma. There are some of the active ingredients for melasma treatment and their functions in Table 1.

\section{Combination of Skin Care Products and Conventional Treatment}

Skin care products can not only be used alone but also combine with other therapy for melasma patients. Skin care products have the effect of repairing the damaged skin barrier, and also can reduce the adverse reactions of routine therapeutic approaches, so as to improve the tolerance and compliance of melasma patients. This may improve the success rate of melasma treatment. Meanwhile, skin care products can also be used as maintenance treatment to avoid the recurrence of melasma.

\section{Combination of Skin Care Products and Drug Therapy}

Oral medication is generally not the first choice for the treatment of melasma, in most cases, it is used for overindication. $^{5}$ Topical drug application is the preferred treatment option for melasma, however, the adverse 
Table I Active Ingredients and Functions of Skin Care Product

\begin{tabular}{|c|c|c|}
\hline Active Ingredient & Function & References \\
\hline Titanium dioxide & Sunscreening properties & [20] \\
\hline Niacinamide & $\begin{array}{l}\text { Inhibiting melanogenesis through interfering with the interaction between keratinocytes and melanocytes, } \\
\text { inhibiting melanin transfering by modulating the protease-activated receptor (PAR-2), antioxidant by } \\
\text { increasing NADPH, improving the skin barrier function by upregulating the synthesis of ceramides and } \\
\text { stimulating keratinocyte differentiation }\end{array}$ & {$[23,34]$} \\
\hline Vitamin C & $\begin{array}{l}\text { Antioxidant, inhibiting tyrosinase through interaction with copper ions at tyrosinase active sites, dcreasing } \\
\text { melanogenesis, UV-protective by neutralizing free radicals }\end{array}$ & [24] \\
\hline Vaseline & Moisturizing and recovering the skin barrier through AHR pathway & {$[28,40]$} \\
\hline Tranexamic acid & Anti-inflammatory and anti-angiogenic by suppressing of ET-I & [30] \\
\hline Resveratrol & $\begin{array}{l}\text { Direct and indirect tyrosinase inhibitor by decreasing transcription and post-transcriptional regulation, } \\
\text { anti-inflammatory by activating PTEN/PI3K/AKT pathways, regulating inflammatory mediators and affecting } \\
\text { arachidonic acid metabolism, UV Protectant through direct antioxidant effects and activation of the nuclear } \\
\text { factor erythroid 2-related factor (Nrf2) pathway }\end{array}$ & {$[31]$} \\
\hline Orchid extracts & Phenolic compounds have antioxidant activities & [32] \\
\hline Arbutin & Reduces tyrosinase activity & [33] \\
\hline Soybean extract & $\begin{array}{l}\text { Antioxidant through raising cellular glutathione content and glutathione S-transferase activity, preventing } \\
\text { antioxidant enzyme depletion, decreasing } \mathrm{H}_{2} \mathrm{O}_{2} \text { formation, and preventing ornithine decarboxylase } \\
\text { induction and DNA degradation, suppressing melanosome metastasis by inhibiting the protease-activated } \\
\text { receptor (PAR-2) }\end{array}$ & [34] \\
\hline Aloe extracts & $\begin{array}{l}\text { Moisturizing, anti-inflammatory by inhibiting cytokines, ROS production, and JAKI-STATI/3 signaling } \\
\text { pathway, antioxidant through free radical scavenging, metal chelation, and enzyme regulation, reducing the } \\
\text { production of melanin by inhibiting the hydroxylation of tyrosine to DOPA and oxidation of DOPA, } \\
\text { promoting wound healing by increasing cell migration via phosphorylation of Cdc42 and RakI, cytokines, } \\
\text { and growth factors }\end{array}$ & {$[35,36]$} \\
\hline $\begin{array}{l}\text { Extract of Camellia } \\
\text { sinensis }\end{array}$ & $\begin{array}{l}\text { Moisturizing by reducing TEWL value, anti-inflammation by inhibiting the production of NO, PGE (2) and } \\
\text { TNF-a and reducing the expression of COX and iNOS gene, anti-oxidation by scavenging reactive oxygen } \\
\text { species and enhancing the activity of oxidase in keratinocytes, and tyrosinase inhibitor }\end{array}$ & [37] \\
\hline Cysteamine & Anti-oxidation and inhibition of tyrosinase and peroxidase activity & [38] \\
\hline Glycerol & Moisturizing by increasing the water content in the superficial and reducing TEWL value & [4I] \\
\hline Hyaluronic acid & Moisturizing and anti-inflammatory & [42] \\
\hline $\begin{array}{l}\text { Fruit acid (alpfa } \\
\text { hydroxy acids) }\end{array}$ & Accelerating the exfoliation of keratinocytes, moisturing, repair skin barrier and antioxidant & [43] \\
\hline
\end{tabular}

reactions like skin irritation and contact dermatitis are easy to occur after the use of topical drugs such as hydroquinone, retinoic acid and azelaic acid. ${ }^{5}$ Many of these comfortlessness can be relieved with the use of skin care products. A placebo-controlled, single-blind trial conducted by Ibrahim et $\mathrm{al}^{42}$ has found that the subjects with hyaluronic acid(HA) had fewer side effects and the recurrence rate was lower than that of hydroquinone or glycolic acid alone after 12-week treatment of melasma patients. The author believes that this is related to the moisturizing and anti-inflammatory effects of HA. Skin care products have the functions of moisturizing, anti-inflammation, repairing skin barrier and so on. Rational use of skin care products can increase the tolerance of patients, reduce the recurrence rate, and improve patient satisfaction. 


\section{Skin Care Products Combined with Laser Therapy}

Laser therapy, one of the important methods for the treatment of melasma, explodes and reduces facial melanophores through photoelectric effect. However, phototherapy can also cause various degrees of damage to the skin barrier, resulting in adverse reactions such as erythema, burning sensation, postinflammatory pigmentation, hypopigmentation, aggravation of primary skin lesions and even scars. ${ }^{5}$ Skin care products with whitening ingredients can reduce the formation and diffusion of melanin. ${ }^{3}$ A prospective study conducted by Polnikorn et $\mathrm{al}^{44}$ showed that laser therapy combined with whitening products can effectively improve the skin lesions of patients with melasma with low recurrence rate (5.71\%). Moisturizing products are the mainstay of treatment for xerosis and pruritus. ${ }^{45}$ Skin care products for promoting wound healing can promote wound healing after laser and minimally invasive surgery by adding aloe, polypeptide, amino acid, hyaluronic acid and other ingredients. ${ }^{3}$ Therefore, laser therapy combined with skin care products can effectively relieve discomfort of patients, repair skin barrier and prevent postinflammatory pigmentation and hypopigmentation.

\section{Skin Care Products Combined with Chemotherapy}

Chemical peeling acts on the surface of the skin by chemicals, resulting in controllable destruction and exfoliation of the skin and promoting new skin regeneration, so as to reduce spots. ${ }^{5}$ A clinical comparative study shows that the combined use of trichloroacetic acid and ascorbate can improve pigmentation and mMASI score of patients with melasma better than trichloroacetic acid alone. ${ }^{46}$ Another clinical trial confirmed that the use of moisturizing cream (Winona special care cream) after fruit acid skin revitalizing procedure can significantly improve the discomfort and plays a good auxiliary role for melasma in increasing the stratum corneum water content and sebum content and restoring the skin barrier. ${ }^{47}$ In summary, chemical peeling combined with skin care products containing whitening, moisturizing, antiinflammatory and anti-allergic ingredients can help improve the skin lesions of patients with melasma, alleviate postoperative discomfort and improve patient satisfaction.

\section{Conclusion}

At present, medical skin care products have become an important part of the administration of melasma. These above studies demonstrated that various types of medical skin care products have played different roles in the prevention and treatment of melasma, but there still lack of large sample, multicenter, randomized, double-blind, controlled experiment, and the evaluation criteria are not completely unified. Therefore, more relevant clinical observation and basic research are needed. Cosmetic dermatologists are supposed to choose appropriate skin care products and treatment programs according to the skin type, condition and expectation of patient. In the future, with the further study of the effective components and biological activities of skin care product, it is expected to bring better prospects for the treatment of melasma.

\section{Funding}

There is no funding to report.

\section{Disclosure}

The authors report no conflicts of interest for this work.

\section{References}

1. Rajanala S, Maymone M, Vashi NA. Melasma pathogenesis: a review of the latest research, pathological findings, and investigational therapies. Dermatol Online J. 2019;25(10):13030. doi:10.5070/ D32510045810

2. Shankar K, Godse K, Aurangabadkar S, et al. Evidence-based treatment for melasma: expert opinion and a review. Dermatol Ther (Heidelb). 2014;4(2):165-186. doi:10.1007/s13555-014-0064-z

3. Li L, Li H, Wei L, et al. Guide to the application of skin care products in dermatology. Chin J Dermatol Venereol. 2015;29(06):553-555.

4. Lee DJ, Lee J, Ha J, et al. Defective barrier function in melasma skin. J Eur Acad Dermatol Venereol. 2012;26(12):1533-1537.

5. Rongya Y, Jin C. Consensus of experts on phototherapy and repair of chloasma. J Pract Dermatol. 2020;13(02):65-69.

6. Shanshan H, Li L, Li H. Application of medical skin care products in dermatology. Skin Dis and Venereal Dis. 2008;(03):13-14.

7. Kang WH, Yoon KH, Lee ES, et al. Melasma: histopathological characteristics in 56 Korean patients. $\mathrm{Br} J$ Dermatol. 2002;146 (2):228-237. doi:10.1046/j.0007-0963.2001.04556.x

8. Speeckaert R, Van Gele M, Speeckaert MM, et al. The biology of hyperpigmentation syndromes. Pigment Cell Melanoma Res. 2014;27 (4):512-524. doi:10.1111/pcmr.12235

9. Kang HY, Suzuki I, Lee DJ, et al. Transcriptional profiling shows altered expression of wnt pathway- and lipid metabolism-related genes as well as melanogenesis-related genes in melasma. J Invest Dermatol. 2011;131(8):1692-1700. doi:10.1038/jid.2011.109

10. Enomoto A, Yoshihisa Y, Yamakoshi T, et al. UV-B radiation induces macrophage migration inhibitory factor-mediated melanogenesis through activation of protease-activated receptor- 2 and stem cell factor in keratinocytes. Am J Pathol. 2011;178(2):679-687. doi:10.1016/j.ajpath.2010.10.021

11. Esposito A, Brianezi G, de Souza NP, et al. Exploring pathways for sustained melanogenesis in facial melasma: an immunofluorescence study. Int J Cosmet Sci. 2018;40(4):420-424. doi:10.1111/ics.12468

12. Yoshida M, Takahashi Y, Inoue S. Histamine induces melanogenesis and morphologic changes by protein kinase A activation via $\mathrm{H} 2$ receptors in human normal melanocytes. $J$ Invest Dermatol. 2000;114(2):334-342. doi:10.1046/j.1523-1747.2000.00874.x 
13. Malaviya R, Morrison AR, Pentland AP. Histamine in human epidermal cells is induced by ultraviolet light injury. $J$ Invest Dermatol. 1996;106(4):785-789. doi:10.1111/1523-1747.ep12346356

14. Inomata S, Matsunaga $\mathrm{Y}$, Amano S, et al. Possible involvement of gelatinases in basement membrane damage and wrinkle formation in chronically ultraviolet B-exposed hairless mouse. J Invest Dermatol. 2003;120(1):128-134. doi:10.1046/j.1523-1747.2003.12021.x

15. Kwon SH, Hwang YJ, Lee SK, et al. Heterogeneous pathology of melasma and its clinical implications. Int J Mol Sci. 2016;17(6):824. doi:10.3390/ijms 17060824

16. Merle C, Laugel C, Baillet-Guffroy A. Effect of UVA or UVB irradiation on cutaneous lipids in films or in solution. Photochem Photobiol. 2010;86 (3):553-562. doi:10.1111/j.1751-1097.2009.00690.x

17. Baldwin H, Santoro F, Lachmann N, et al. A novel moisturizer with high sun protection factor improves cutaneous barrier function and the visible appearance of rosacea-prone skin. $J$ Cosmet Dermatol. 2019;18(6):1686-1692. doi:10.1111/jocd.12889

18. Sarkar R, Ghunawat S, Narang I, et al. Role of broad-spectrum sunscreen alone in the improvement of melasma area severity index (MASI) and melasma quality of life index in melasma. $J$ Cosmet Dermatol. 2019;18(4):1066-1073.

19. Lakhdar H, Zouhair K, Khadir K, et al. Evaluation of the effectiveness of a broad-spectrum sunscreen in the prevention of chloasma in pregnant women. J Eur Acad Dermatol Venereol. 2007;21 (6):738-742. doi:10.1111/j.1468-3083.2007.02185.x

20. Fatima S, Braunberger T, Mohammad TF, et al. The role of sunscreen in melasma and postinflammatory hyperpigmentation. Indian J Dermatol. 2020;65(1):5-10. doi:10.4103/ijd.IJD_295_18

21. Boukari F, Jourdan E, Fontas E, et al. Prevention of melasma relapses with sunscreen combining protection against $\mathrm{UV}$ and short wavelengths of visible light: a prospective randomized comparative trial. $J$ Am Acad Dermatol. 2015;72(1):189-190. doi:10.1016/j.jaad.2014.08.023

22. D'Mello SA, Finlay GJ, Baguley BC, et al. Signaling pathways in melanogenesis. Int $J$ Mol Sci. 2016;17(7):1144. doi:10.3390/ ijms 17071144

23. Sarkar R, Arora P, Garg KV. Cosmeceuticals for hyperpigmentation: what is available? J Cutan Aesthet Surg. 2013;6(1):4-11. doi:10.4103/0974-2077.110089

24. Telang PS. Vitamin $\mathrm{C}$ in dermatology. Indian Dermatol Online J. 2013;4(2):143-146. doi:10.4103/2229-5178.110593

25. Bronzina E, Clement A, Marie B, et al. Efficacy and tolerability on melasma of a topical cosmetic product acting on melanocytes, fibroblasts and endothelial cells: a randomized comparative trial against 4\% hydroquinone. J Eur Acad Dermatol Venereol. 2020;34 (4):897-903. doi:10.1111/jdv.16150

26. Draelos ZD. Cosmeceuticals: what's real, what's not. Dermatol Clin. 2019;37(1):107-115. doi:10.1016/j.det.2018.07.001

27. Nolan K, Marmur E. Moisturizers: reality and the skin benefits. Dermatol Ther. 2012;25(3):229-233. doi:10.1111/j.15298019.2012.01504.x

28. Xiaofeng H, Yinjuan W, Meihua G, et al. Observation on the efficacy of Pang's flawless transparent day cream in improving chloasma and its skin barrier function. Skin Dis Venereal Dis. 2014;36 (03):125-128.

29. Elias PM, Menon G, Wetzel BK, et al. Evidence that stress to the epidermal barrier influenced the development of pigmentation in humans. Pigment Cell Melanoma Res. 2009;22(4):420-434. doi:10.1111/j.1755-148X.2009.00588.x

30. Kim SJ, Park JY, Shibata T, et al. Efficacy and possible mechanisms of topical tranexamic acid in melasma. Clin Exp Dermatol. 2016;41 (5):480-485. doi:10.1111/ced.12835

31. Na JI, Shin JW, Choi HR, et al. Resveratrol as a multifunctional topical hypopigmenting agent. Int J Mol Sci. 2019;20(4):956. doi:10.3390/ijms20040956
32. Tadokoro T, Bonte F, Archambault JC, et al. Whitening efficacy of plant extracts including orchid extracts on Japanese female skin with melasma and lentigo senilis. J Dermatol. 2010;37(6):522-530. doi:10.1111/j.1346-8138.2010.00897.x

33. Dun H, Fanglan W, Xiaolan X, et al. Study on the therapeutic effect and mechanism of arbutin on yellow brown spot rat model. Chin J Modern Med. 2018;28(34):6-10.

34. Levin J, Momin SB. How much do we really know about our favorite cosmeceutical ingredients? J Clin Aesthet Dermatol. 2010;3 (2):22-41.

35. Sanchez M, Gonzalez-Burgos E, Iglesias I, et al. Pharmacological update properties of aloe vera and its major active constituents. Molecules. 2020;25(6):1324. doi:10.3390/molecules25061324

36. Ghafarzadeh M, Eatemadi A. Clinical efficacy of liposome-encapsulated Aloe vera on melasma treatment during pregnancy. J Cosmet Laser Ther. 2017;19(3):181-187. doi:10.1080/ 14764172.2017.1279329

37. Xiaofeng H, Haiyang L, Meihua G, et al. Studies on the effects of Camellia oleifera, Euphorbia angustifolia, Mulberry Fruit and Chonglou on the proliferative activity and tyrosinase of melanocytes. Chin J Dermatol. 2015;48(02):133-136.

38. Atallah C, Charcosset C, Greige-Gerges H. Challenges for cysteamine stabilization, quantification, and biological effects improvement. $J$ Pharm Anal. 2020;10(6):499-516. doi:10.1016/j.jpha.2020.03.007

39. Wenli L, Jun C, Xiuqiong X. Clinical observation on the treatment of chloasma with the essence of green thorn fruit, purslane, Dianshan tea and Panax notoginseng. Skin Dis Venereal Dis. 2020;542 (06):789-792.

40. Czarnowicki T, Malajian D, Khattri S, et al. Petrolatum: barrier repair and antimicrobial responses underlying this "inert" moisturizer. J Allergy Clin Immunol. 2016;137(4):1091-1102. doi:10.1016/j. jaci.2015.08.013

41. Korponyai C, Szel E, Behany Z, et al. Effects of locally applied glycerol and xylitol on the hydration, barrier function and morphological parameters of the skin. Acta Derm Venereol. 2017;97 (2):182-187. doi:10.2340/00015555-2493

42. Ibrahim ZA, Gheida SF, El MG, et al. Evaluation of the efficacy and safety of combinations of hydroquinone, glycolic acid, and hyaluronic acid in the treatment of melasma. $J$ Cosmet Dermatol. 2015;14 (2):113-123. doi:10.1111/jocd.12143

43. Meng HM, Li L. The effect and clinical application of fruit acid.J. Dermatol Venereol. 2014;36(03):155-157.

44. Polnikorn N. Treatment of refractory melasma with the MedLite C6 Q-switched Nd: YAGlaser and alpha arbutin: a prospective study. $J$ Cosmet Laser Ther. 2010;12(3):126-131. doi:10.3109/ 14764172.2010.487910

45. Danby SG, Andrew PV, Brown K, et al. An investigation of the skin barrier restoring effects of a cream and lotion containing ceramides in a multi-vesicular emulsion in people with dry, eczema-prone, skin: the RESTORE study phase 1. Dermatol Ther (Heidelb). 2020;10 (5):1031-1041. doi:10.1007/s13555-020-00426-3

46. Soliman MM, Ramadan SA, Bassiouny DA, et al. Combined trichloroacetic acid peel and topical ascorbic acid versus trichloroacetic acid peel alone in the treatment of melasma: a comparative study. $J$ Cosmet Dermatol. 2007;6(2):89-94. doi:10.1111/j.14732165.2007.00302.X

47. Qin P, Jie Z, Cheng Y, et al. Effect of medical skin care products on skin barrier function after skin activation with fruit acid. 2013 National Annual meeting of Integrated traditional Chinese and Western Medicine on Dermatological Diseases; Xiamen, Fujian, China; 2013. 


\section{Publish your work in this journal}

Clinical, Cosmetic and Investigational Dermatology is an international, peer-reviewed, open access, online journal that focuses on the latest clinical and experimental research in all aspects of skin disease and cosmetic interventions. This journal is indexed on CAS.
The manuscript management system is completely online and includes a very quick and fair peer-review system, which is all easy to use. Visit http://www.dovepress.com/testimonials.php to read real quotes from published authors.

Submit your manuscript here: https://www.dovepress.com/clinical-cosmetic-and-investigational-dermatology-journal 